\title{
Towards understanding the cutting and fracture mechanism in ceramic matrix composites
}

\author{
O. Gavalda Diaz ${ }^{\mathrm{a}}$, D.A. Axinte ${ }^{\mathrm{a}, *}$ \\ ${ }^{a}$ Rolls-Royce University Technology Centre in Manufacturing and On-Wing \\ Technology, Faculty of Engineering, University of Nottingham, NG7 2RD, UK
}

\begin{abstract}
Ceramic Matrix Composites (CMCs) are increasingly used for the manufacture of high-value parts for several industries such as the aerospace, nuclear and automotive. Nevertheless, their heterogenic, anisotropic and brittle nature make difficult to characterise the machining process and therefore, an in-depth understanding of the cutting mechanics is needed. In this regard, this paper aims to understand the different behaviours of CMCs while employing orthogonal cutting. The first part of this article proposes a novel theoretical approach to explain the different types of cutting behaviours (fracture and shear cutting) based on the inelastic and orthotropic properties of the CMC's by using a high imaging system and measuring the cutting forces. The second part aims to understand the cutting and fracture mechanism by developing for the first time a specific analytical model for each of the three main orthotropic orientations, defined by the three main relative fibre orientations respect to the feed direction, which are found in cutting of CMCs. This is approached by the calculation of the specific cutting energy needed to fracture the CMC's during cutting (energy release rate, $G_{c}$ ) using fracture mechanics and cutting theories. This analytical model has been successfully validated for a Carbon/Carbon composite with the experimental data obtained for the brittle cutting and by introducing the concept of a rising R-curve in cutting models. Moreover, comparing the results obtained for the energy release rate for the brittle and semi-ductile
\end{abstract}


mode, it is observed that the material experiences an important change in the energy release rate according to the brittle-to-semi-ductile transition occurring while reducing the depth of cut. Finally, a novel monitoring method based on the vibrations of the sample has been found successful to understand the type of crack formation appearing while cutting CMCs. Keywords: Machining, Ceramic Matrix Composites, Orthogonal cutting, Fracture mechanism, Crack formation 2015 MSC: 00-01, 99-00

\section{Introduction}

\subsection{Ceramic Matrix Composites (CMCs)}

Composite materials have increased in demand in many different industries because of their excellent mechanical characteristics such as the strength-to-weight, stiffness-to-weight, corrosion and fatigue resistance. Composites are formed from two or more materials, resulting in properties that can not be achieved with monolithic materials. Commonly, one of the materials acts as a matrix and the other one as a reinforcement. The matrix is in charge of spreading the stress to the fibres and protecting them from external damages while providing the final shape of the component. On the other hand, the reinforcement provides greater mechanical properties. [1].

Depending on the type of reinforcement, composite materials are classified in particulate, flake and fibre composites [2]. Fibre composite can also be classified as short or long fibres. Short fibres slightly increase the properties of the matrix randomly in all directions, while long fibres highly increase the properties in specific directions. In aerospace applications,

\footnotetext{
${ }^{*}$ Corresponding author

Email address: Dragos.Axinte@nottingham.ac.uk (D.A. Axinte)
} 
long fibre composites are consistently used in order to reduce weight by just having preferential directions with high mechanical properties. Composite materials can also be classified depending on the nature of the matrix: Polymer Matrix Composites (PMCs), Metal Matrix Composites (MMCs) and Ceramic Matrix Composites (CMCs) [1, 3]. PMCs are often refereed as FRP (Fibre Reinforced Polymer) and have a polymeric matrix (i.e. Epoxy or Phenolic) reinforced with brittle fibres (i.e. Carbon or Glass). These materials are being chosen as a replacement of light metal alloys such as those based on aluminium or titanium. MMCs are used for applications requiring higher temperature in service than the PMCs and the most common structure are Boron or Silicon-Carbide fibres embedded in a metal matrix (i.e. Titanium or Steel) [1].

Ceramic Matrix Composites have been the preferred candidate for the replacement of some elevated temperature materials in the modern industries. In aerospace, CMCs have been introduced in gas turbine engines as a replacement of some superalloys [4] and in rocket nozzles [5]. For nuclear applications, CMCs are under consideration to be used as a structural material for fusion and fission reactors [6]. CMCs have also been employed in frictional applications as braking systems in cars or aircrafts [1]. The CMC's success in extremes applications is due to their high mechanical and chemical performances at high temperature, such as fatigue and oxidation resistance [4]. Moreover, compared to the monolithic ceramics, the reinforcement in CMCs displays improved fracture toughness and mechanical strength. A common CMC material used in a wide range of industrial applications is the Carbon/Carbon $(\mathrm{C} / \mathrm{C})$ in which high strength carbon fibres are embedded in a graphite matrix. This combination makes the $\mathrm{C} / \mathrm{C}$ an excellent candidate for ultra-high specific strength applications. Further reinforced ceramics found in the aerospace industry are the $\mathrm{C} / \mathrm{SiC}$ and $\mathrm{SiC} / \mathrm{SiC}$ where Carbon or Silicon Carbide fibres are inserted in 
a Silicon Carbide matrix which possesses better corrosion resistance than Carbon [7]. Due to this growing demand on CMCs, fundamental orthogonal cutting tests are needed for a better understanding of the machining process.

\subsection{Orthogonal cutting in composite materials}

In so-called orthogonal cutting, a single cutting edge wider than the work-piece is used to unidirectionally cut along the surface. The cutting is assumed to be uniform along the cutting edge, reducing the problem into a two-dimensional scenario [8]. The cutting mechanism in composite materials has been analytically and experimentally investigated using orthogonal cutting. Pwu and Hocheng [9] analysed the cut quality in unidirectional composites by modelling the chip length and the fracture mechanism. The model considered orthotropic behaviour and beam theories to understand the chip formation but only considered fibres placed perpendicularly to the cutting edge. Sahraie Jahromi and Bahr [10] proposed an analytical model to calculate the cutting forces applying bending theories on single fibres and extrapolating to the whole composite by using the fibre volume fraction. Nevertheless, the model was only developed for one specific fibre orientation with simulated results showing some discrepancies with some experimental data. Bhatnagar et. al [11] correlated the cutting force with the shear properties of composite materials for different fibre orientations and proposed an empirical relation to calculate the cutting force. However, the mechanics of the system were not modelled and therefore, the empirical solution has limitations in model applicability for other types of composites such as the CMCs. Wang and Zhang [12] studied the surface quality of unidirectional composites by evaluating the influence of different rake angles and fibre orientations; while this is useful information, the aspects of different cutting and fracturing modes depending on the depth and width of 
cut were not considered. Moreover, several Finite Element Models (FEM) using cohesive theories, elasto-plastic behaviour and fracture mechanisms were studied to predict the cutting forces for different fibre orientations [13, 14, 15]. While this work can provide useful specific data, an analytical model might offer a better understanding of the parameters and materials properties affecting the cutting mechanism.

Furthermore, all these models have been proposed for PMCs or MMCs where a ductile cut formation is clearly predominant. In contrast with these, in CMCs a transition between semi-ductile to brittle cutting can often be found, affecting the surface damage created by the crack propagation. In this respect, as the CMCs possess a brittle matrix, it could be commented that considering its different mechanical behaviours under cutting was a novel commitment necessary for the understanding of the cutting process.

\subsection{Fracture mechanics in cutting}

Fracture mechanics has been used to some extent in orthogonal cutting by considering the notion of fracture toughness for the understanding of the crack generation [8, 16]. Patel et al. [17] and Wang et al. [18] used orthogonal cutting as a method to calculate some materials properties such as the fracture toughness and the yield stress in isotropic materials such as metals and polymers. Liao and Axinte [19] used fracture mechanics to predict the chip formation mechanism in cortical bones, also considered as a composite structure. Nonetheless, the mechanical approach for the three cutting orientations used (longitudinal, across and transverse) was simplified into one final analytical expression, loosing accuracy on the explanation of the mechanical behaviour. Theoretical approaches for chip formation in isotropic materials have been proposed to understand the bending and rotation mechanism that chips can suffer in cutting and in peel-up tests [20]. 
However, due to the isotropy of the materials tested, an anisotropic behaviour on the fracture toughness and therefore of the cutting mechanism was not considered.

Some researchers have been interested in the so-called ductile-to-brittle transition that specially brittle materials can experience during the machining at relative low uncut chip thickness. It has been commented [21]; that, depending on the specific cutting energy, the machining can be accomplished by plastic deformation (ductile behaviour) or by crack propagation (brittle behaviour). The comprehension of this transition point is a key factor for the understanding of the material cracking and therefore, the workpiece surface quality in machining brittle materials [22]. Nevertheless, further research has not been documented in the interpretation of the ductile-to-brittle transition between cutting modes in composites materials such as CMCs where due to their brittle matrix, this phenomenon can occur at low uncut chip thickness. Commonly CMCs are manufactured with long reinforcing fibres creating three mutually perpendicular planes of material symmetry. This implies that the elastic material properties are defined by nine coefficients and therefore, CMCs are not completely anisotropic but they are termed orthotropic [2].

In an attempt to fill the research gaps related to cutting orthotropic materials that can display ductile-to-brittle behaviour, e.g CMCs, this paper aims to propose a mechanism to interpret the cutting and fracture behaviour for each of the three main orthotropic orientations. In this respect, an analytical cutting model based on the inelastic behaviour and fracture mechanics of orthotropic brittle composite materials is proposed for the understanding of the surface quality and integrity in machining. The model has been validated experimentally by analysing the machining forces, cracks behaviour, vibrations and surface damages. This work might be an interesting lead for further research in other traditional machining 
process such as drilling, milling or turning for CMCs and similar materials.

\section{Experimental methodology}

To study the cutting mechanism in CMCs, orthogonal tests with different fibre orientations have been performed to observe the response of the brittle matrix-composite and obtain unique data (e.g. forces, vibrations and crack formation mechanisms) not previously found in the literature and needed for the validation of the analytical approaches.

Samples $(25 \times 3 \times 5 \mathrm{~mm})$ of bidirectional Carbon-Carbon with an approximate Young Modulus along the fibre direction of $80 \mathrm{GPa}$ and $5 \mathrm{GPa}$ out of the fibres direction, have been water-jet cut. Afterwards, the samples have been carefully polished to achieve the final dimensions and glued with a structural epoxy resin to an aluminium plate in order to have greater clamping surface and to avoid any induced damage in the composite structure.

An in-house developed 4-axis miniature machine tool [23], with a repeatability of $0.1 \mu \mathrm{m}$ of the positioning stage, was adapted for performing orthogonal cutting tests. A solid carbide cutting edge with rake angle $\alpha=8^{\circ}$, clearance angle $\gamma=8^{\circ}$ and edge radius $\mathrm{r}=5 \mu \mathrm{m}$ was used as previously done in [19]. In order to reduce the friction force and therefore to meet the setup recommended for orthogonal cutting, the width of the sample was thinner than the width of the cutting edge $(2 \mathrm{~mm})$. The cutting speed chosen for the trials was $30 \mathrm{~mm} / \mathrm{min}$ since this allowed to work with higher depths of cut and easily understand the cutting mechanism. The cutting forces were measured with a 3-component miniature dynamometer (Kistler 9317B) at an acquisition rate of $10 \mathrm{kHz}$ and the vibrations with a compact single axe accelerometer PCB 352C23 from Piezotronics (Fig,1b, 1 c). After the cutting trials, the machined surfaces were analysed by Scanning Electron Microscopy (Philips XL30 ESEM-FEG) to observe the surface damage. 


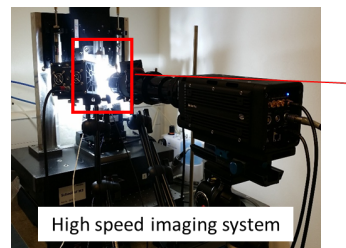

(a)

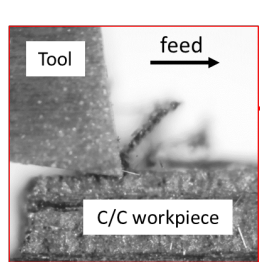

(b)

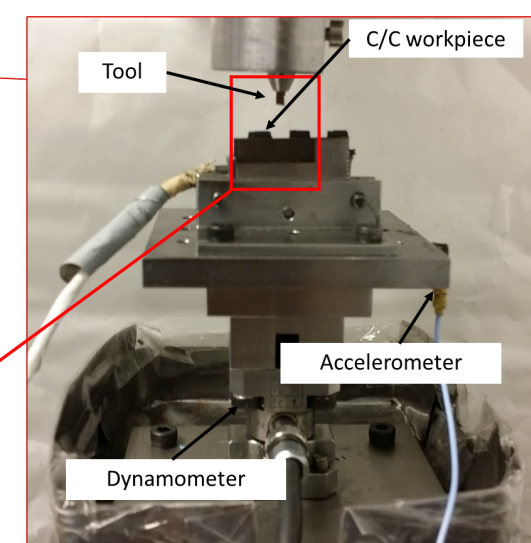

(c)

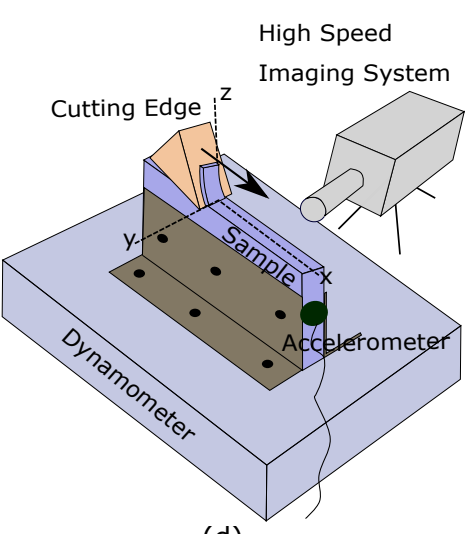

(d)

Figure 1: Orthogonal cutting set-up (a) general view of the high speed imaging system (b) view from the high imaging system (c) close-up of the cutting zone (d) scheme of the set-up

To understand the crack behaviour, a High Speed Camera Y4-S2-M and an objective $\mathrm{K} 2 \mathrm{CF}-4$ with a long distance high magnification lens (K2 infinity video lens) was used (Fig 1 1a). The cutting process was recorded at a resolution of $1024 \times 1024$ and a recording speed of 1000 fps. In order to explain the cutting mechanism observed and to get the data needed for the analytical approaches, the video was synchronised with the force and vibration signals.

\section{Ductile-to-brittle transition in cutting CMCs}

CMCs are commonly formed by a ceramic matrix reinforced with bidirectional fibres. Nevertheless, analysing the composite at a local area (as the situation encountered during the cutting process at a typical chip thickness) the composite structure can be simplified as a unidirectional. In the case where the depth of cut is higher than the thickness of a unidirectional ply the tool faces an environment with bidirectional fibres which can be studied as two unidirectional cases. Based on the different shear mechanisms (elastic and inelastic [24]) that CMCs experience depending on the fibre orientation, a novel theoretical approach defining the different cutting 
behaviours has been developed. Therefore, this study considers three main scenarios related to the cutting direction and the shear stresses: longitudinal, across and transverse fibres (see Fig,2].

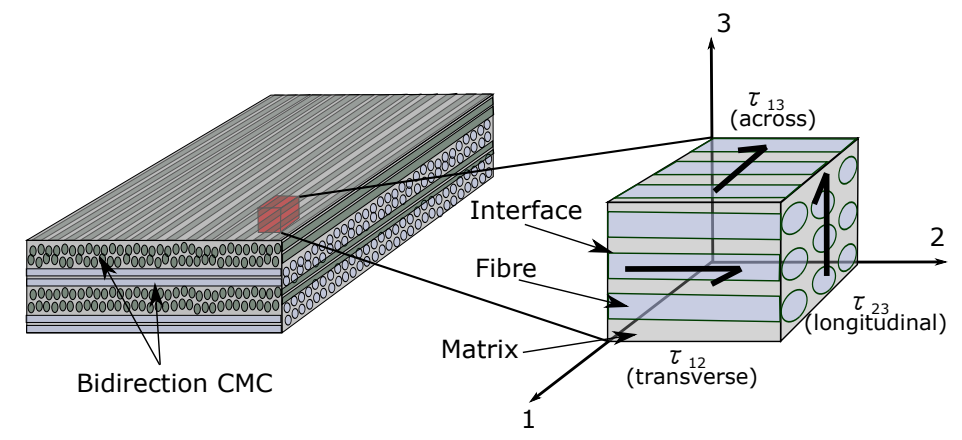

Figure 2: Schematic on a bidirectional structure of a CMC with a close-up showing the main directions of shear stress

Compared to monolithic ceramics that possess mostly a linear shear behaviour, the inelastic and hence bilinear behaviour of CMC's plays an important role in defining the machining modes. The shear through the fibres involves two main mechanisms: matrix failure and fibre failure [25]. For small shear stresses $\left(\tau<\tau_{M C S}^{c o m p}\right)$, fibres and matrix resist with a higher shear modulus $\left(G^{c o m p}\right)$, while when the stress reaches the critical value (Matrix Shear Strength, $\tau_{M C S}^{c o m p}$ ) the matrix fails debonding from the fibres and only the fibres resists against the shear stress with a lower shear modulus $\left(G^{\text {fibres }}\right)$, as shown in Fig, 3. The material is completely sheared at a stress higher than the Ultimate Shear Strength $\left(\tau_{U S S}^{c o m p}\right)$. This difference in shear behaviour between monolithic and reinforced ceramics is useful to explain the different cutting modes appearing in the cutting of CMCs depending on the fibre orientation.

\subsection{Cutting along longitudinal fibres}

The cutting process along longitudinal fibres can be considered in three cutting modes: (i) composite shear; (ii) matrix shear; and (iii) matrix fracture. 


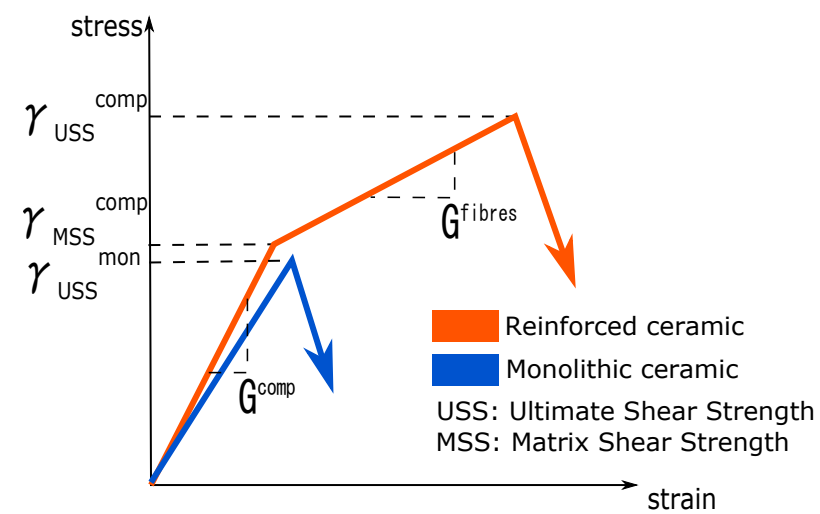

Figure 3: Linear and bilinear shear behaviour of monolithic and reinforced brittle materials (adapted from [11])

- (i) Composite shear: appears when the cutting shear stress is higher than the ultimate shear strength $\left(\tau_{U S S}^{c o m p}\right)$ of the whole CMC. In this case, the material is cut in a shear mode and pull out as a form of discontinuous chips due to the heterogeneity and fragile nature of the chips (See Fig, 4 a).

- (ii) Matrix shear: appears when the shear stress applied is lower than the ultimate shear strength $\left(\tau_{U S S}^{c o m p}\right)$ but higher than the matrix shear strength $\left(\tau_{M S S}^{c o m p}\right)$. This condition is unique for cutting composites with longitudinal fibres since the shear plane is formed through the fibres. In this case, the material is cut by a combination of matrix debonding due to the shear and bending or buckling of the fibres due to the movement of the tool (See Fig. $4 \mathrm{~b}$ ).

- (iii) Matrix fracture: appears when the shear stress applied does not reach the matrix shear strength $\left(\tau_{M S S}^{c o m p}\right)$ and therefore, the material cannot be sheared. Instead, the material is fractured (in a brittle mode) by crack propagation in the cutting plane. Since the lowest fracture toughness of the composite material is found in interface between the fibres and the matrix, the crack propagates through this interface in the cutting direction (See Fig,4 ). Due to this anisotropic 
toughness, the crack does not divert to the surface, creating a brittle continuous offcut formation [8].

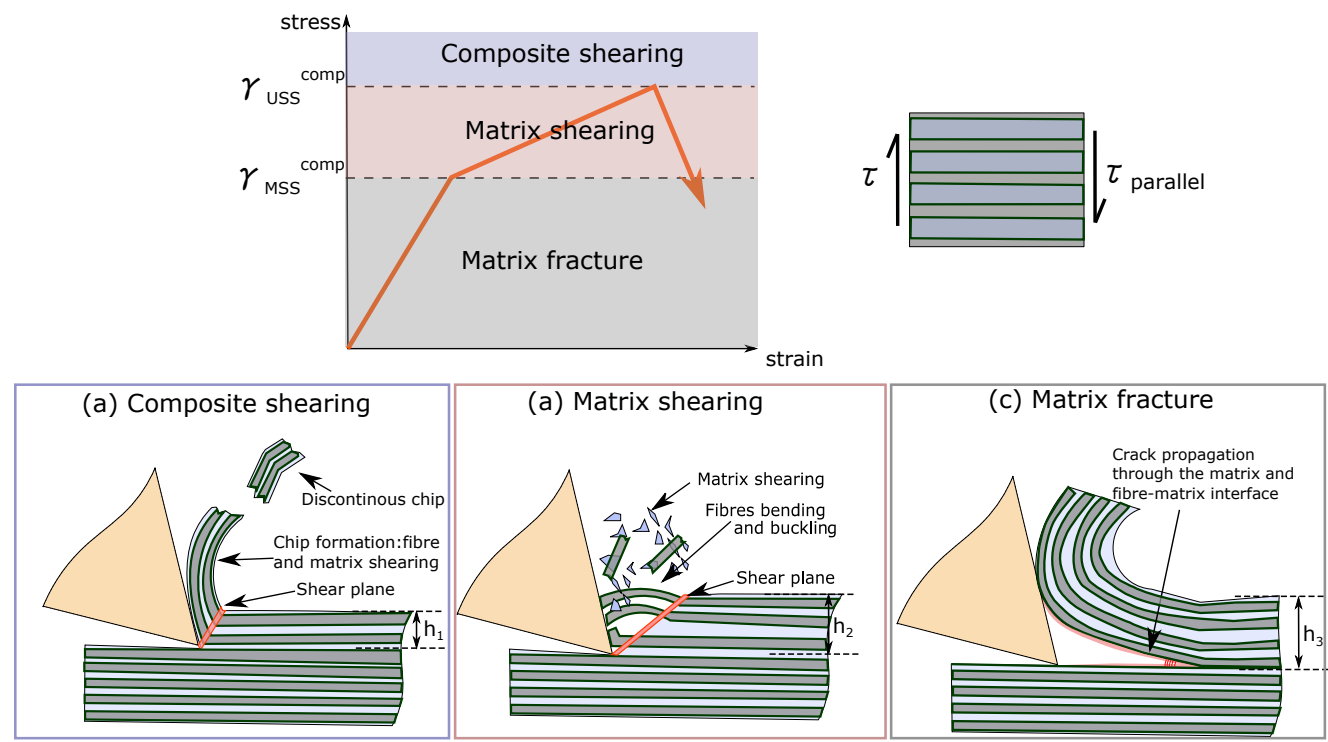

Figure 4: Cutting modes in longitudinal fibres (a) composite shear (b) matrix shear (c) matrix fracture with $h_{1}<h_{2}<h_{3}$

As previously stated in the literature, the main characteristics of the material behaviours in orthogonal cutting could be revealed by studying the uncut chip thickness. Therefore, orthogonal cutting tests were performed to empirically validate the cutting modes at different chip thickness (from $5 \mu \mathrm{m}$ until $170 \mu \mathrm{m}$ ) keeping a constant width of cut of $1 \mathrm{~mm}$. Frames from the high speed imaging system have been used to capture the materials behaviour and correlated to the cutting forces signals in Fig.5. As shown in Fig 5 a for the composite shearing mode, the material is removed in the form of discontinuous chips, shearing both fibres and matrix which yields steady forces in the cutting and thrust direction. In the case of the matrix shearing mode (Fig, $5 \mathrm{~b}$ ) the fibres cannot be sheared and they are clearly bent and buckled; as the cutting is stable and continuous the cutting forces are also constant. Finally, in the case of matrix fracture (Fig 5 c) a big peak in the cutting force is found during the first contact of the tool with the material when the main crack is formed, afterwards the cutting force is 
constant at a lower value since the crack is steadily propagated due to a peeling-up action of the fibres from the matrix.

(a)
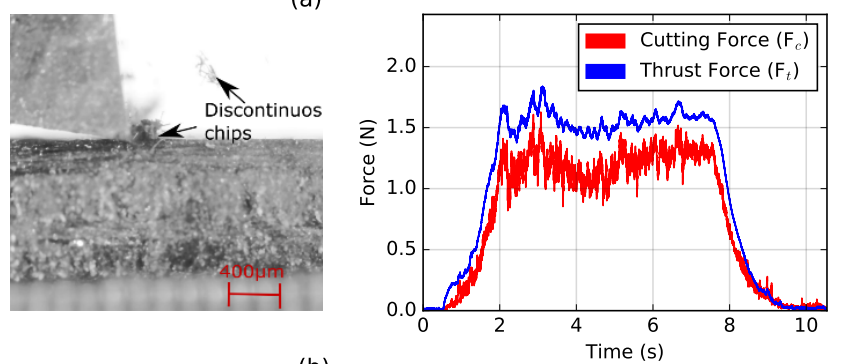

(b)
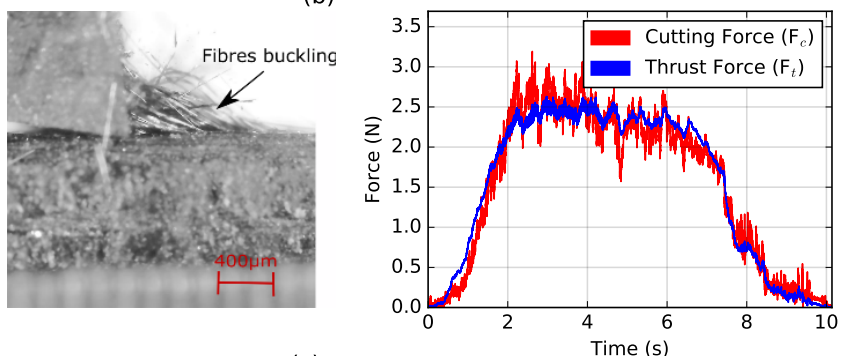

(c)
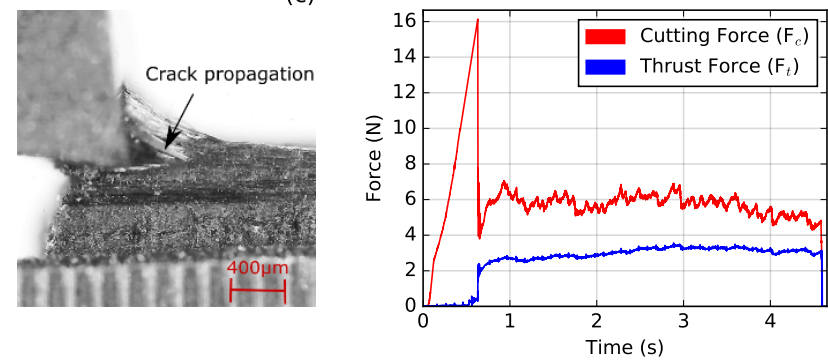

Figure 5: Frames showing the cutting mechanism and the forces in longitudinal fibres for (a) composite shearing $(\mathrm{h}=5 \mu \mathrm{m})$, (b) matrix shearing $(\mathrm{h}=30 \mu \mathrm{m})$ and (c) matrix fracture $(\mathrm{h}=170 \mu \mathrm{m})$

\subsection{Cutting along across fibres}

The cutting process of across fibres has been segregated in two cutting modes: (i) matrix shearing and (ii) matrix fracture. In this scenario, the shear plane evades to be generated through the fibres choosing a lower energy path through the matrix and interfaces. This indicates that the material does not experience an inelastic behaviour and it just behave as a monolithic ceramic possessing a critical strength $\tau_{U S S}^{m o n}$ (see Fig 6) . 
- (i) Matrix shearing: appears when the shear stress applied is higher than the ultimate shear strength $\left(\tau_{U S S}^{m o n}\right)$ of the matrix. In this respect, the material can be removed by a linear shear mode characteristic of monolithic ceramics (See Fig.6a).

- (ii) Matrix fracture: appears when the shear stress applied does not reach the ultimate shear strength $\left(\tau_{U S S}^{m o n}\right)$ thus the composite is removed by fracture. Firstly, the crack propagates in the cutting plane and it finally tends to rotate to the surface forming a discrete offcut (as previously described in the literature for an isotropic material having a constant toughness in the orthogonal cutting plane [8]). As explained for longitudinal fibres, the crack tends to propagate through the interface between the fibre and the matrix (See Fig $6 \mathrm{~b}$ ).
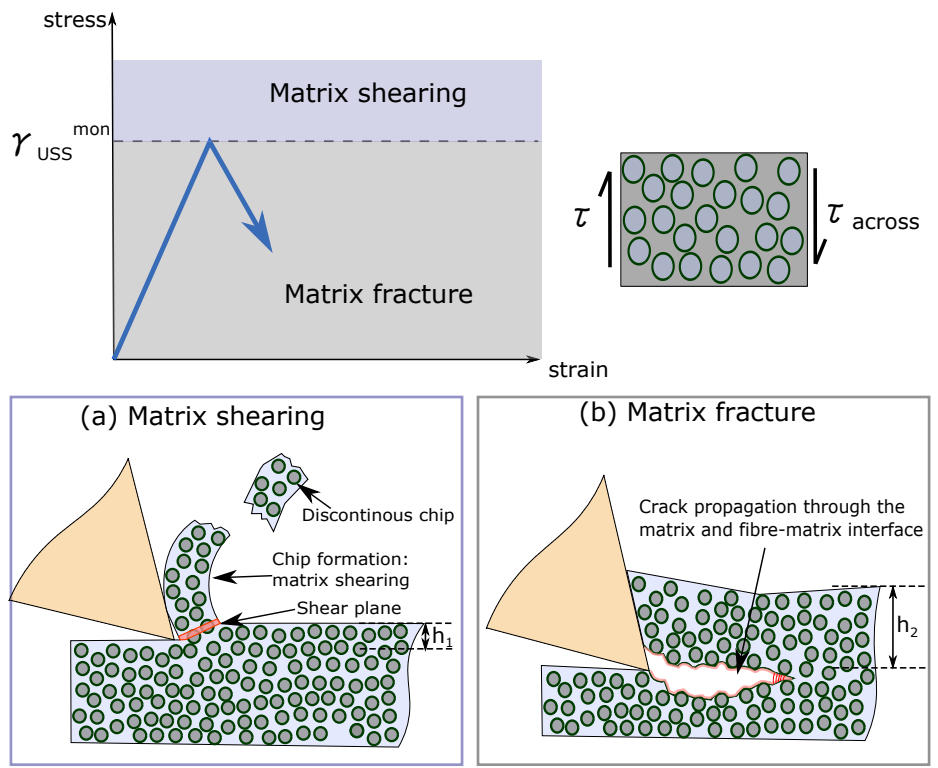

Figure 6: Cutting modes in across fibres (a) matrix shear (b) matrix fracture with $h_{1}<h_{2}$

As done for longitudinal fibres, the $\mathrm{C} / \mathrm{C}$ has been orthogonally cut at different uncut chip thickness (from $5 \mu \mathrm{m}$ until $150 \mu \mathrm{m}$ ) keeping a constant width of cut of $1 \mathrm{~mm}$ to empirically observe the cutting modes. In Fig.7 the matrix shearing mechanism is shown with the formation of discontinuous 
chips and steady forces. On the other hand, Fig.7b shows the matrix fracture, that due to the discontinuous chip formation, the cutting force tends to suffer rapid drops to zero.
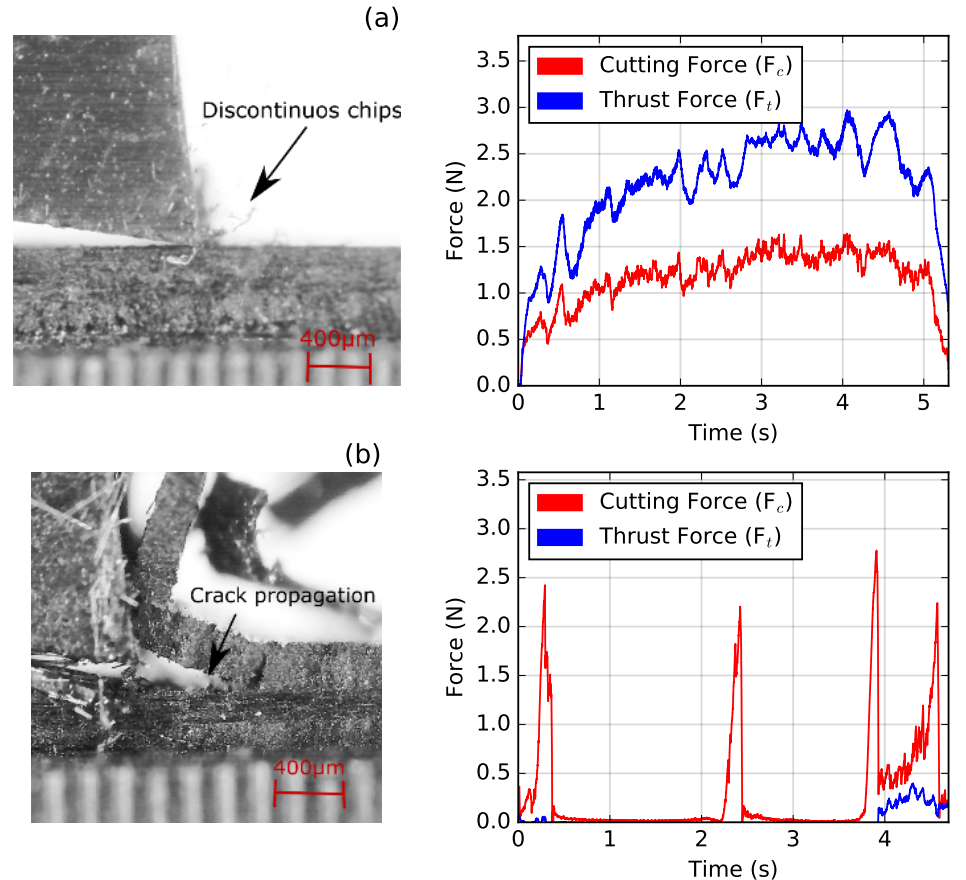

Figure 7: Frames showing the cutting mechanism and the forces in across fibres for (a) matrix shearing $(\mathrm{h}=5 \mu \mathrm{m})$ and $(\mathrm{b})$ matrix fracture $(\mathrm{h}=110 \mu \mathrm{m})$

\subsection{Cutting along transverse fibres}

The cutting mechanism in transverse fibres can also be explained in two cutting modes: matrix sharing (i) and matrix fracture (ii).

- (i) Matrix shearing: the same principle applied for the across orientations is found for transverse fibres. If the cutting shear stress is higher than the ultimate shear strength of the matrix $\left(\tau_{U S S}^{m o n}\right)$ the material can be removed by shear cutting. The shear plane is formed along the matrix avoiding the fibres and therefore, minimising the cutting energy (see Fig, 8a). As observed for across fibres, in transverse fibres the composite acts as a monolithic ceramic and in this case the fibres are cut due to the tool indentation. 
- (ii) Matrix fracture: appears when the shear stress applied does not reach the ultimate shear strength $\left(\tau_{U S S}^{m o n}\right)$. In the case of transverse fibres, the fibre-matrix interface is found along the vertical direction, hence the crack formation also appears along this axis (See Fig, $8 \mathrm{~b}$ ). Therefore, the brittle offcut cannot be classified in any type previously found in the literature, since the material is not removed by crack propagation in the cutting plane but by brittle bending along the vertical axis.
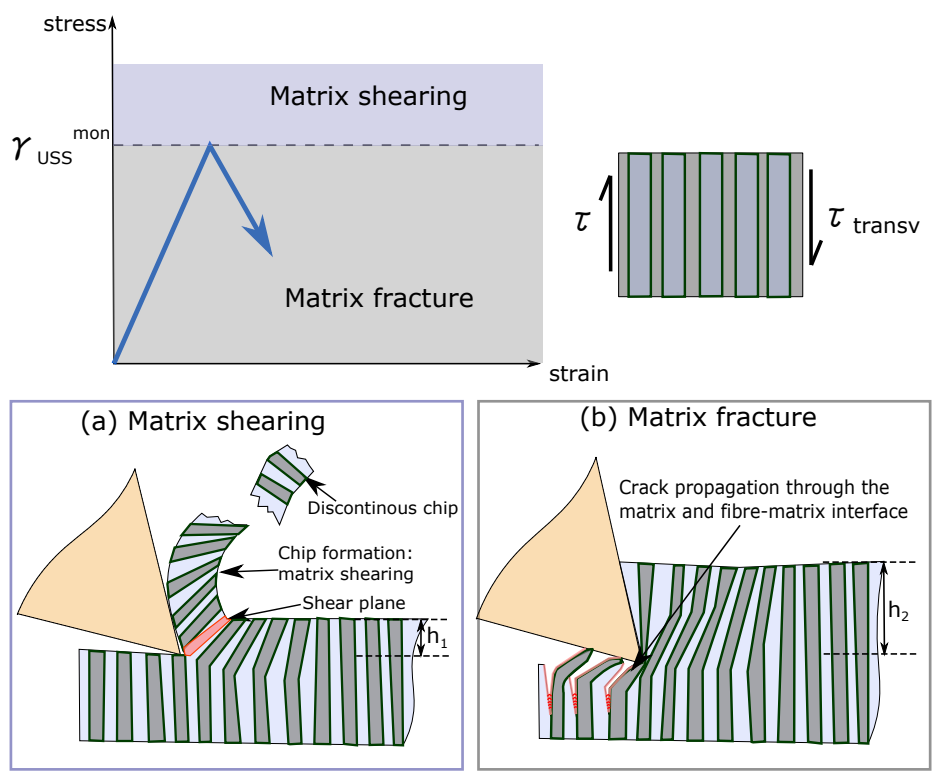

Figure 8: Cutting modes in transverse fibres (a) composite shear (b) composite fracture with $h_{1}<h_{2}$

Orthogonal cutting test have been performed for transverse fibres at different uncut chip thickness (from $5 \mu \mathrm{m}$ until $120 \mu \mathrm{m}$ ) keeping a width of cut of $0.2 \mathrm{~mm}$. In Fig. $9 \mathrm{a}$ a discontinuous chip formation has been recorded with the camera causing steady forces. In Fig $9 \mathrm{~b}$ the frame shows how the region being bent accumulates damages (darker zone) due to the crack propagation. In this case, since the cut is continuous, the forces do not have big drops in value.

Once this transition between mechanisms is understood, a deep under- 
(a)
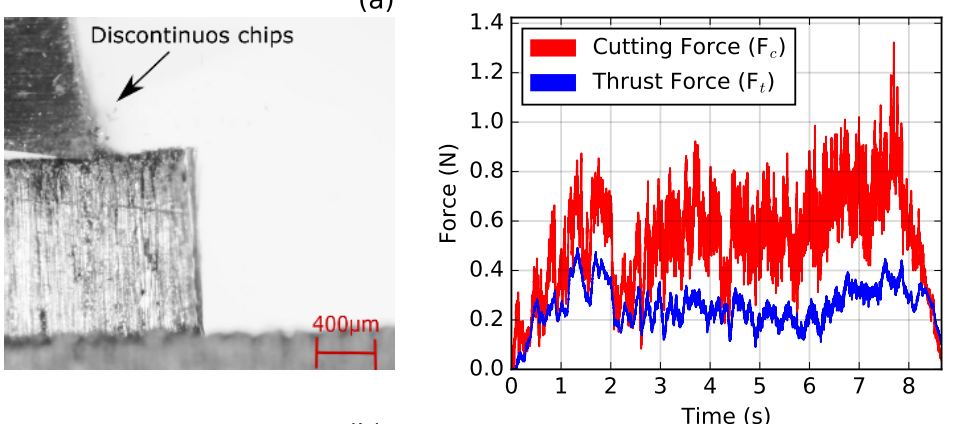

(b)
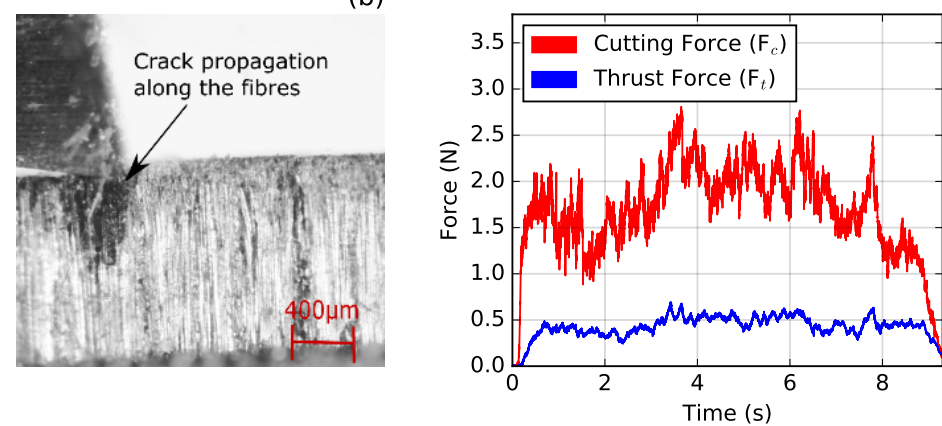

Figure 9: Frames showing the cutting mechanism and the forces in transverse fibres for (a) matrix shearing $(\mathrm{h}=5 \mu \mathrm{m})$ and $(\mathrm{b})$ matrix fracture $(\mathrm{h}=100 \mu \mathrm{m})$

standing of the brittle and shearing domains has been done by analytically modelling the energy release rate.

\section{Modelling the brittle regime: fracture cutting of CMCs}

As previously shown, when the depth of cut is increased, the material tends to fracture along the fibre-matrix interface in an elastic domain. Hence, this section proposes a novel analytical approach to facilitate the understanding of the fracture cutting in orthotropic brittle materials by calculating the energy release rate based on the mechanism found, for the three orientations, in the experimental section.

As previously validated in the literature, beam theory can be used to understand orthogonal cutting [26, 16]. Several authors [19] agreed than in orthogonal cutting the crack propagation is a combination of Mode I (opening mode) and Mode II (shear mode). Nonetheless, after the experi- 
mental section it is postulated that this approach might not be accurate for orthotropic materials and depending of the fibre orientations the cracking mode might vary.

As the material is being removed in a brittle mode, the work applied by the external forces is transferred to the material in the form of elastic strain energy $(\mathrm{U})$ and potential energy for the fracture (П):

$$
W_{\text {external forces }}=U+\Pi
$$

Assuming that the crack occurs in a load controlled mode [27]:

$$
W_{\text {external forces }}=2 U
$$

Therefore, the specific cutting energy available for the crack to propagate $(\mathrm{G})$ can be related to the elastic strain energy as:

$$
G=\frac{d \Pi}{d A}=\frac{1}{w} \frac{d U(a)}{d a}
$$

Where $\mathrm{w}$ is the width of the cut and $a$ is the crack length.

The fracturing mode occurs if the specific energy $(G)$ applied to the crack zone is higher than the threshold called energy release rate or fracture energy $\left(G_{c}\right)[27$.

$$
G \geq G_{c}
$$

As aforementioned, an accurate model needs to explain each of the cutting conditions separately, therefore three different approaches have been developed to explain the three main orthotropic conditions in which cutting can occur in a CMC. 


\subsection{Fracture cutting along longitudinal fibres}

Continuous chip formation occurs during the fracture cutting through longitudinal fibres and, for that reason two different fracture scenarios could appear while cutting. The first fracture mechanism arises during the first contact of the cutting tool with the material (tool indentation). The second one appears once the main crack has been formed (peeling-up action).

\subsubsection{Tool indentation}

Before the cutting edge indents the material, the tool faces a situation where the material needs to be initially cracked. Consequently, the tool applies an axial compressive stress with no thrust force (as shown in Fig.5c). As shown in Fig 10a, the compressive stress causes a deformation $\left(\Delta_{1}\right)$ of the material. The elastic energy density (U) in compression can be calculated as:

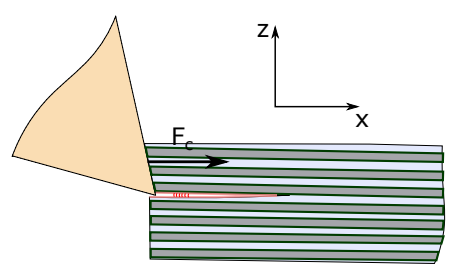

(a)
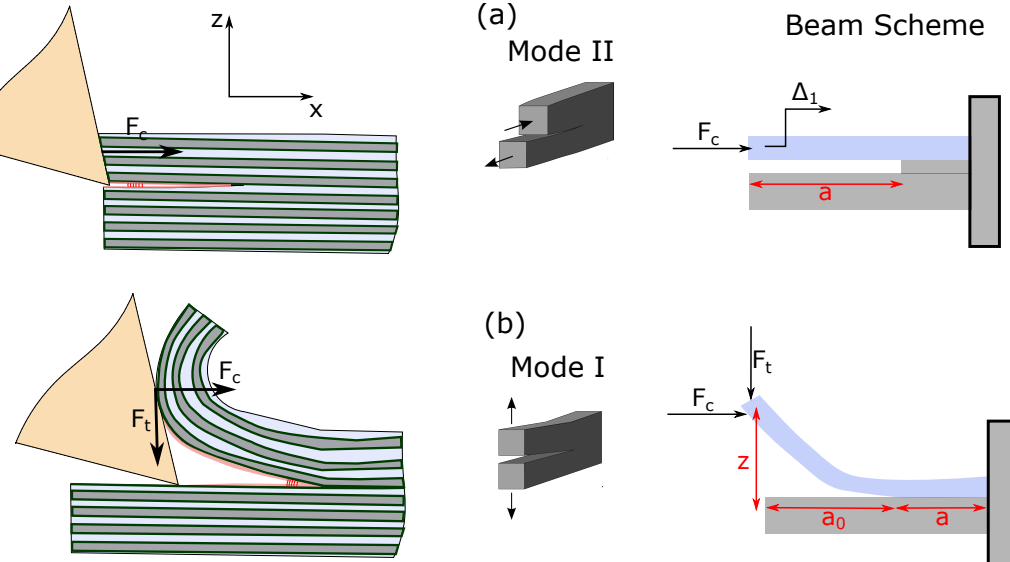

(b)
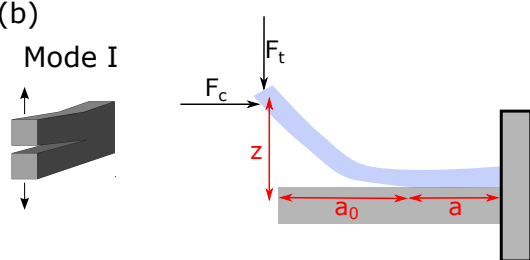

Figure 10: Mechanical approach for the fracture cutting of longitudinal fibres during the (a) tool indentation and (b) peel-up action

$$
\delta U=\frac{\sigma_{x}^{2}}{2 E_{x}}=\frac{F_{c}^{2}}{2 E_{x}(w h)^{2}}
$$

Where $E_{x}$ is the Young Modulus along the fibre axis, $F_{c}$ is the cutting force, $\mathrm{w}$ the width of the sample and $\mathrm{h}$ the depth of cut.

Therefore, the elastic energy stored within the body is: 


$$
U=\int_{0}^{a} \delta U d V=\frac{F_{c}^{2} a}{2 E_{x} w h}
$$

Where $\mathrm{a}$ is the crack length formed during the indentation process.

Once the elastic energy is calculated, using Eq3 the specific energy available for crack propagation can be written as:

$$
G=\frac{F_{c}^{2}}{2 E_{x} w^{2} h}
$$

During the tool indentation, the thrust force is zero or negligible compared to the cutting force (See Fig $\sqrt[5 c]{5}$ ). Hence, the energy release rate acting during the tool indentation is due to a shearing mode (mode II). As aforementioned in Eq, 4 , the crack is able to form and propagate if the specific energy is equal or higher than the energy release rate. Eq.8 can therefore calculate the energy release rate during the tool indentation process:

$$
G \geq G_{c}^{I I} \rightarrow G_{c}^{I I}=\frac{F_{c}^{2}}{2 E_{x} w^{2} h}
$$

\subsubsection{Peeling-up action}

Due to the continuous chip formation, the chip is not removed and the crack only propagates along the cutting plane, therefore the tool rake face pushes the material, as shown in Fig.10p.

The chip is exposed to a bending force caused by the cutting $\left(F_{c}\right)$ and thrust force $\left(F_{t}\right)$. The elastic energy density of a bending beam can be calculated as:

$$
\delta U=\frac{M^{2}}{2 E_{x} I}=\frac{\left(F_{c} z-F_{t} x\right)^{2}}{2 E_{x} I}
$$

Where $\mathrm{I}$ is the moment of inertia $\left(I=w h^{3} / 12\right)$ and $\mathrm{x}$ and $\mathrm{z}$ are the distance offset of the forces (shown in Fig 10p). Integrating Eq.9, the elastic 
strain energy is:

$$
U=\int_{0}^{a_{0}+a} \delta U d x=\frac{\left(F_{c} z-F_{t}\left(a_{0}+a\right)\right)^{3}}{6 E_{x} I F_{c}}
$$

Where $a_{0}$ is the main crack formed during the indentation and a is the stable crack happened during the peeling-up action. Nevertheless, due to the continuous chip formation appearing in the brittle cutting of longitudinal fibres, friction between the rake face and the chip should be considered. Therefore the trust and cutting forces contributing to the elastic bending can be calculated as:

$$
\begin{aligned}
& F_{c}^{\prime}=F_{c}-N \mu \sin (\alpha)=F_{c}-\left(F_{c} \cos (\alpha)-F_{t} \sin (\alpha)\right) \mu \sin (\alpha) \\
& F_{t}^{\prime}=F_{t}-N \mu \cos (\alpha)=F_{t}-\left(F_{c} \cos (\alpha)-F_{t} \sin (\alpha)\right) \mu \cos (\alpha)
\end{aligned}
$$

where $\mu$ is the friction coefficient and the $\alpha$ is the rake angle. An approximated value of $\mu$ has been extracted from the literature for the cutting of quasi-isotropic carbon reinforced composite, containing fibres in different directions. [28].

In the case of the peeling up action, the crack propagates due to an opening mode (see Fig 10b). Hence, the energy release rate in mode I dominates the peeling-up mechanism and can be calculated as:

$$
G_{c}^{I}=\frac{6\left(F_{c}^{\prime} z-F_{t}^{\prime}\left(a_{0}+a\right)\right)^{2}}{E_{x} w^{2} h^{3}}
$$

Therefore, Eq.8 and Eq.12 define the specific energy needed to fracture the material while cutting along longitudinal fibres.

\subsection{Fracture cutting along across fibres}

A discrete chip is formed during the brittle elastic cutting of across fibres. Consequently, the crack propagation always occurs due to shear 
(Mode II) on the cutting plane, similarly as found for the tool indentation mechanism in longitudinal fibres (See Fig 11). This hypothesis can again be validated from the force diagram in Fig.7b, where the trust force is null during the crack formation. Hence, the energy release rate in shear mode $\left(G_{c}^{I I}\right)$ causes the crack to propagate during the cutting of across fibres and can be calculated as:

$$
G_{c}^{I I}=\frac{F_{c}^{2}}{2 E_{x} w^{2} h}
$$

Where in this case the Young modulus in the cutting direction $\left(E_{x}\right)$ correspond to the one out of axis.
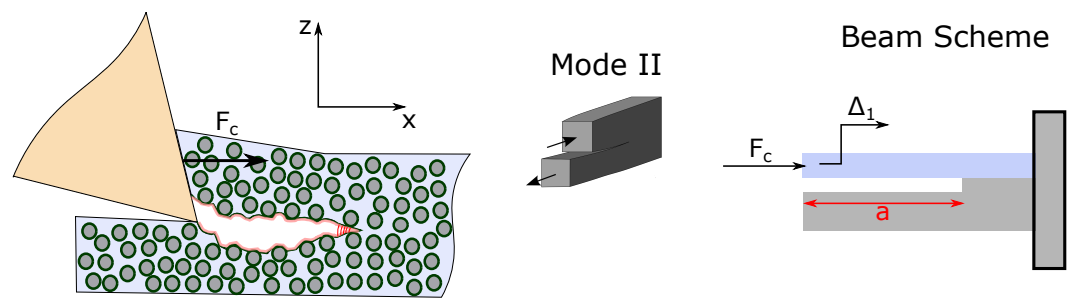

Figure 11: Mechanical approach for the fracture cutting of across fibres

\subsection{Fracture cutting along transverse fibres}

As previously stated, in cutting transverse fibres the composite suffers a brittle behaviour due to the elastic bending along the axis of the fibres caused by the bending force (see Fig, 12).

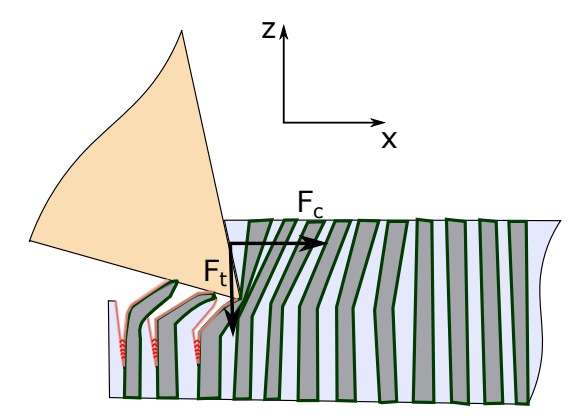

Beam Scheme

Figure 12: Mechanical approach for the fracture cutting of transverse fibres 
The bending force is caused by the cutting $\left(F_{c}\right)$ and the thrust $\left(F_{t}\right)$ forces as shown in Fig, 12, As previously explained, the elastic strain energy can be calculated integrating the elastic energy density obtained for bending:

$$
U=\int_{0}^{a_{0}+a} \delta U d x=\frac{\left(F_{c} a+F_{t} x\right)^{3}}{6 E_{z} I F_{c}}
$$

In this case, the section of the beam is given by the width of the sample (w) and by the bending length (b). The bending length depends on the material voids such as the porosities and flaws, highly found in CMC due to the manufacturing process.

The maximum deflection $\left(\delta_{\max }\right)$ of the central axis shown in Fig. 12 can be calculated using beam theories for a cantilever beam with a force applied at a distance $\mathrm{h}$ from the edge:

$$
\delta_{\max }=\frac{F_{c} a^{2}}{6 E_{z} I}(3(a+h)-a)
$$

Therefore as shown in Fig 13 an average bending distance (b) can be calculated assuming a constant distribution of voids (p):

$$
b=\delta_{\max } / p
$$

Considering that the crack propagates between each Representative Elementary Volume (REV), the energy release rate in opening mode for transverse fibres can be calculated as:

$$
G=\frac{6\left(F_{c} a+F_{t} \delta_{\max }\right)^{2}}{E_{z} w^{2} b^{3}} \frac{b}{L_{R E V}}
$$

Where $L_{R E V}$ is the width of a single REV, as shown in Fig 13 . From the high imaging system, it can be assumed that: $F_{c} a \gg F_{t} \delta_{\max }$. Therefore, the energy release rate in mode I for transverse fibres can be simplified to: 
(a)
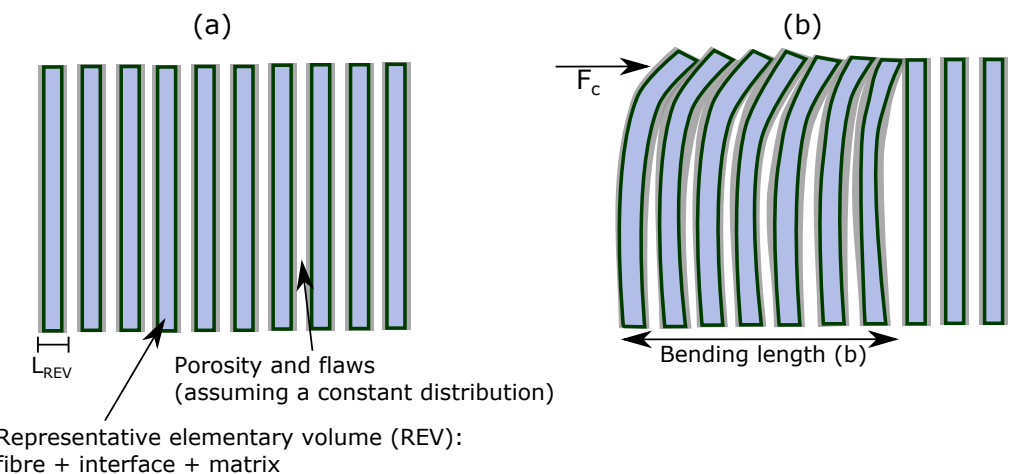

Figure 13: Structure of a CMC considering a constant distribution of porosities and flaws (a) before bending (b) after bending

$$
G_{c}^{I}=\frac{6\left(F_{c} a\right)^{2}}{E_{z} w^{2} b^{3}} \frac{b}{L_{R E V}}
$$

Once the fracture cutting has been explained, an analytical study of the shear cutting has also been proposed.

\section{Modelling the semi-ductile regime: shear cutting of CMCs}

In this case the material is being removed by shear, therefore the work done by the external forces is transferred to the material within the form of shear strain energy, energy dissipation due to friction and potential energy for fracture:

$$
W_{\text {external forces }}=U_{\text {shear }}+E_{\text {friction }}+\Pi
$$

The fracture energy available is applied to the cutting path when the two surfaces of the material are separated by the tool:

$$
F_{c} d \delta_{x}=\int \tau(\gamma) d \gamma d V+E_{f r i c, \alpha}+E_{f r i c, \beta}+G w d a
$$

Where $\int \tau(\gamma) d \gamma$ represents the linear/bilinear shear energy stored by the $\mathrm{CMC}, d \delta_{x}$ represents the tool displacement in the cutting direction and $\mathrm{dV}$ the volume of material sheared. As shear cutting happens in a stable 
mode, the crack distance 'da' can be related to the movement of the tool, therefore it can be assumed that da=d$\delta_{x}\left[\right.$ []. $E_{f r i c, \alpha}$ and $E_{f r i c, \beta}$ represent the friction energy dissipated in the rake and clearance face respectively. The friction forces in both faces can then be expressed as:

$$
\begin{aligned}
& F_{f r i c, \alpha}=\mu\left(F_{c} \cos (\alpha)-F_{t} \sin (\alpha)\right) \\
& F_{f r i c, \beta}=\mu\left(F_{t} \cos (\beta)-F_{c} \sin (\beta)\right)
\end{aligned}
$$

Therefore, Eq20 can be rewritten as:

$$
F_{c}=\tau \gamma h w+F_{f r i c, \alpha} \cos (\alpha)+F_{f r i c, \beta} \cos (\beta)+G w
$$

Where shear strain $(\gamma)$ in shear cutting can be written as [8]:

$$
\gamma=\cot (\phi)+\tan (\phi-\alpha)
$$

Combining Eq 22 and Eq,23 an isolating the energy release rate in shear:

$$
G=\frac{F_{c}}{w}-\frac{F_{f r i c, \alpha}}{w} \cos (\alpha)-\frac{F_{f r i c, \beta}}{w} \cos (\beta)-\tau_{i}^{U S S} h(\cot (\phi)+\tan (\phi-\alpha))
$$

Therefore, the energy release rate in a semi-ductile mode can be calculated using Eq24. As previously stated and as shown in Fig 14 the shear behaviour $\left(\tau_{i}^{U S S}\right)$ depends on the fibre orientation. Moreover, in shear cutting, interlaminar and translaminar fracture toughness appear for the different cutting modes. 


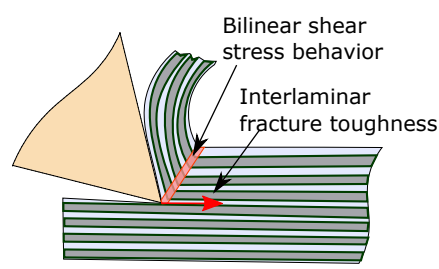

(a)

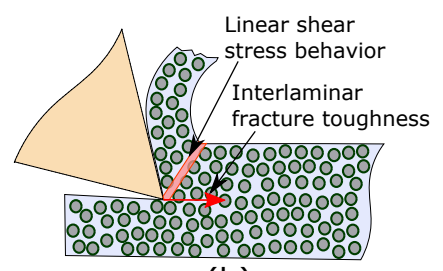

(b)

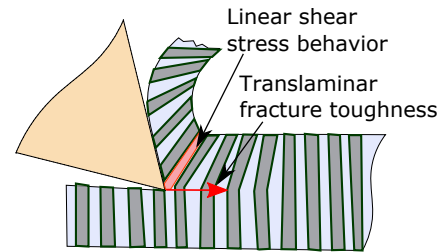

(c)

Figure 14: Shear cutting approach for (a) longitudinal fibres (b) across fibres (c) transverse fibres

\section{Results and discussion relating the proposed models with the experimental trials}

\subsection{Energy release rate in brittle cutting}

\subsubsection{Longitudinal fibres}

The forces in Fig 15 show a clear difference between the two cutting stages previously explained: tool indentation and peel-up action. For the tool indentation, Eq.8 is used to find the $G_{c, l o n g}^{I I}$ during the first force peak. During the stable cutting, the peel-up action occurs and the energy release rate in mode I can be calculated by using Eq.12. Employing a tracking software to the images obtained from the high speed camera, an approximate and quantitative average distances have been estimated $\left(a+a_{0} \approx 500 \mu \mathrm{m}\right.$ and $z \approx 500 \mu \mathrm{m}$ ) for the calculation of $G_{c, l o n g}^{I}$. The vibration signal in Fig 15 a confirm our hypothesis by showing that during the indentation, the tool suffers a big acceleration due to a first unstable crack propagation. Nevertheless, during the peel-up action the crack is propagated stably and therefore the tool does not suffer high vibrations.

\subsubsection{Across fibres}

The energy release rate in cutting across fibres is dominated by a crack propagation in mode II $\left(G_{c, \text { across }}^{I I}\right)$ and can be obtained using Eq 13 . The energy release rate needs to be calculated for the individual peaks appearing in the cutting force plot (as shown in Fig,16). The vibration and force 
(a)

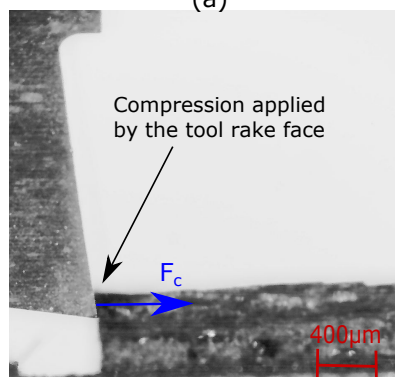

(b)

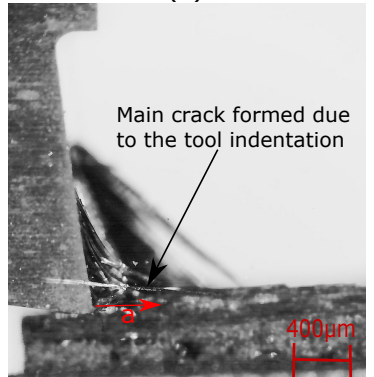

(c)

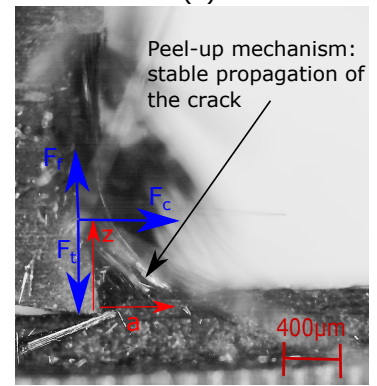

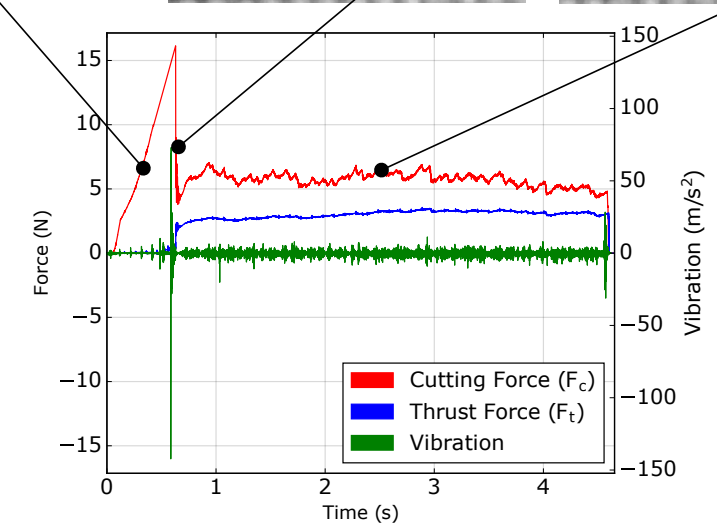

Figure 15: Forces and vibrations correlated with frames from the high speed camera for (a) first compression (b) tool indentation (c) peel-up action

signals in Fig 16 validate our assumptions stating that a discontinuous offcut is formed and the tool suffers a vibration at each new impact with the material. Compared to the acceleration of the tool happening for the indentation in longitudinal fibres, the amplitude of the vibration in across fibres is significantly lower since the Young Modulus along the fibres axis is higher than the one out of the fibres axis. Nevertheless, the amplitude in across fibres is longer on time, meaning that a longer crack is formed.

\subsubsection{Transverse fibres}

The energy release rate in cutting transverse fibres $\left(G_{c, t r a n s}^{I}\right)$ has been calculated using Eq 18 . An approximate value of crack length of a $\approx 500$ $\mu m$ (obtained from the tracking software and the images of the high speed camera) has been considered. In this case, the crack is continuously formed along the $\mathrm{z}$ direction and for that reason the tool does not suffer discrete 
(a)

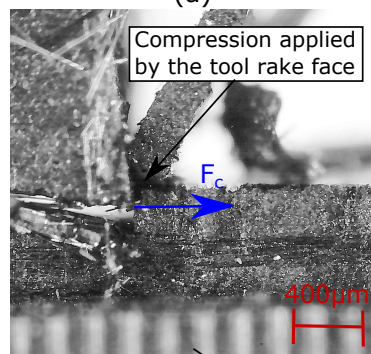

(b)

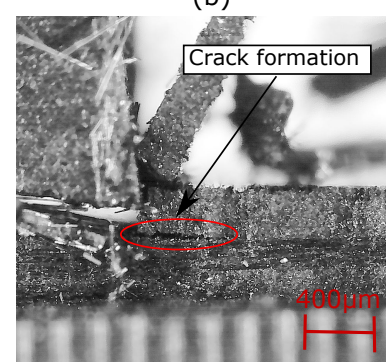

(c)

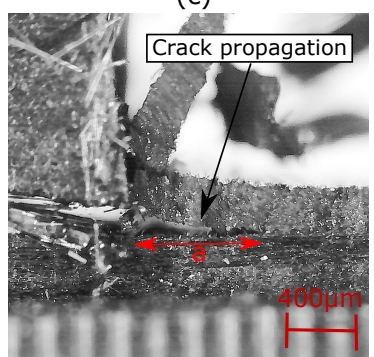

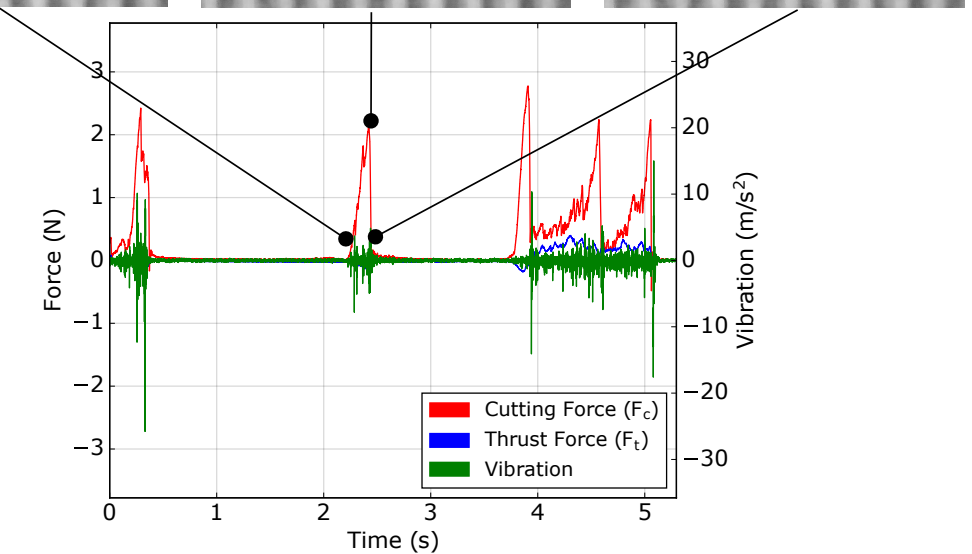

Figure 16: Forces and vibrations correlated with frames from the high speed camera for (a) first compression (b) crack formation (c) crack propagation

vibrations, as shown in Fig.17.

In the authors knowledge, previous research incorporating fracture toughness in cutting has not considered that a great number of materials have a non-constant energy release rate depending on the crack length (rising R-curve) [27]. In the particular case of cutting, it is proved that the cracks formed are small (between 5-500 $\mu \mathrm{m}$ ), therefore the critical energy release rate used for macroscopic tests should not be considered for the cutting models. In the case of the interlaminar fracture toughness of the $\mathrm{C} / \mathrm{C}$, the material possess a rising R-curve for mode I and II [29, 30]. The curves for $\mathrm{C} / \mathrm{C}$ have been digitized to obtain the values of energy release rate for short cracks formation (between 200 and $500 \mu \mathrm{m}$ as observed from the high speed system). Fig 18 show a comparison between the theoretical and experimental results for the energy release rate in mode I and II respectively. In both cases, the values obtained from the model (blue and magenta) are 
(a)

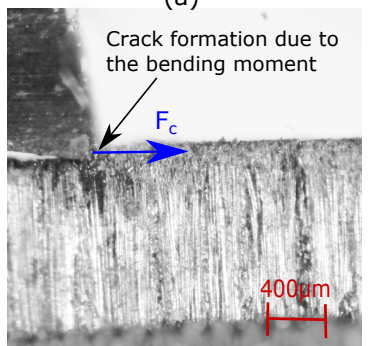

(b)

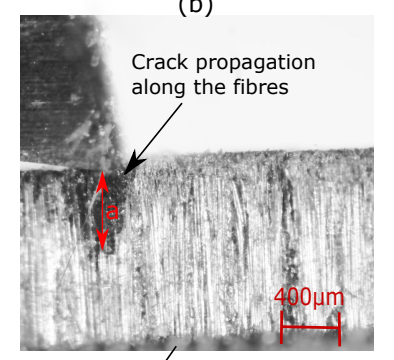

(c)

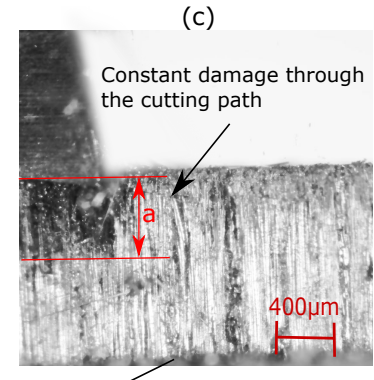

Figure 17: Forces and vibrations correlated with frames from the high speed camera for (a) first instance of bending (b) first crack formation (c) multiple cracks formed in the material

similar to the ones extracted from the rising R-curve (green). The only case were more imprecise results were found was for the $G_{c, l o n g}^{I}$. This error might come due to the averaging of the different experimental values $\left(a+a_{0}, \mathrm{y}\right.$ and $\left.\mu\right)$ used for this specific cutting condition. Moreover, the graph shows that the values obtained assuming a flat $R$-curve (red bands) are significantly higher and therefore non appropriate for the validation of the cutting model.

A SEM analysis has been performed to the machined surface after the brittle cutting (see Fig,19). The results show that the damages found are due to the crack propagation through the fibre axis. For this reason, in the model validation the interlaminar fracture toughness of the Carbon/Carbon has been used as a reference. 

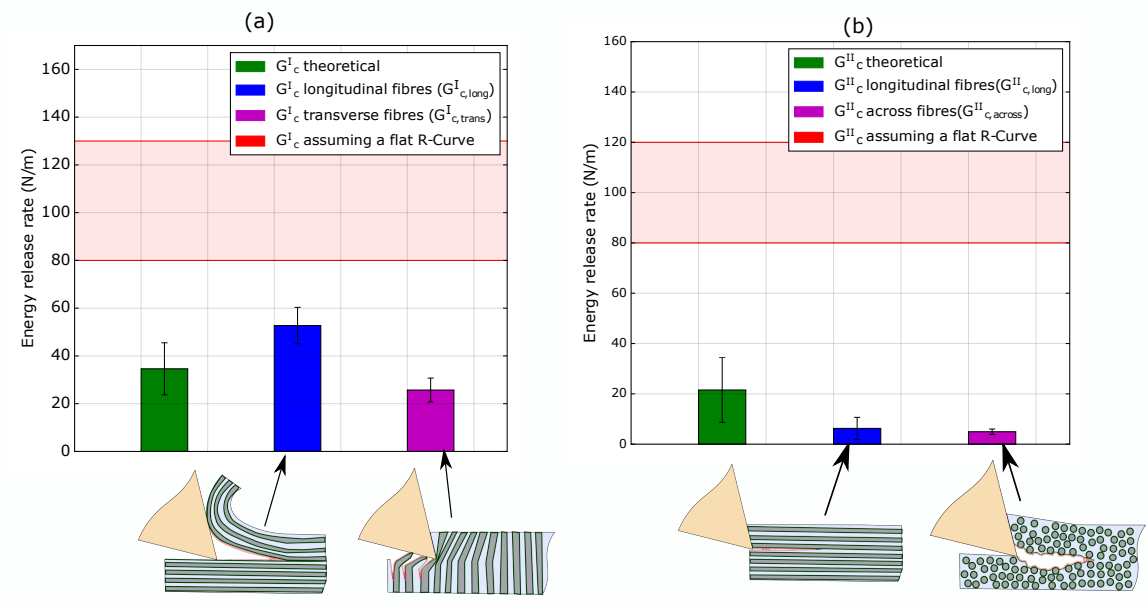

Figure 18: Average results for the energy release rate in (a) Mode I: opening mode (b) Mode II: shear mode
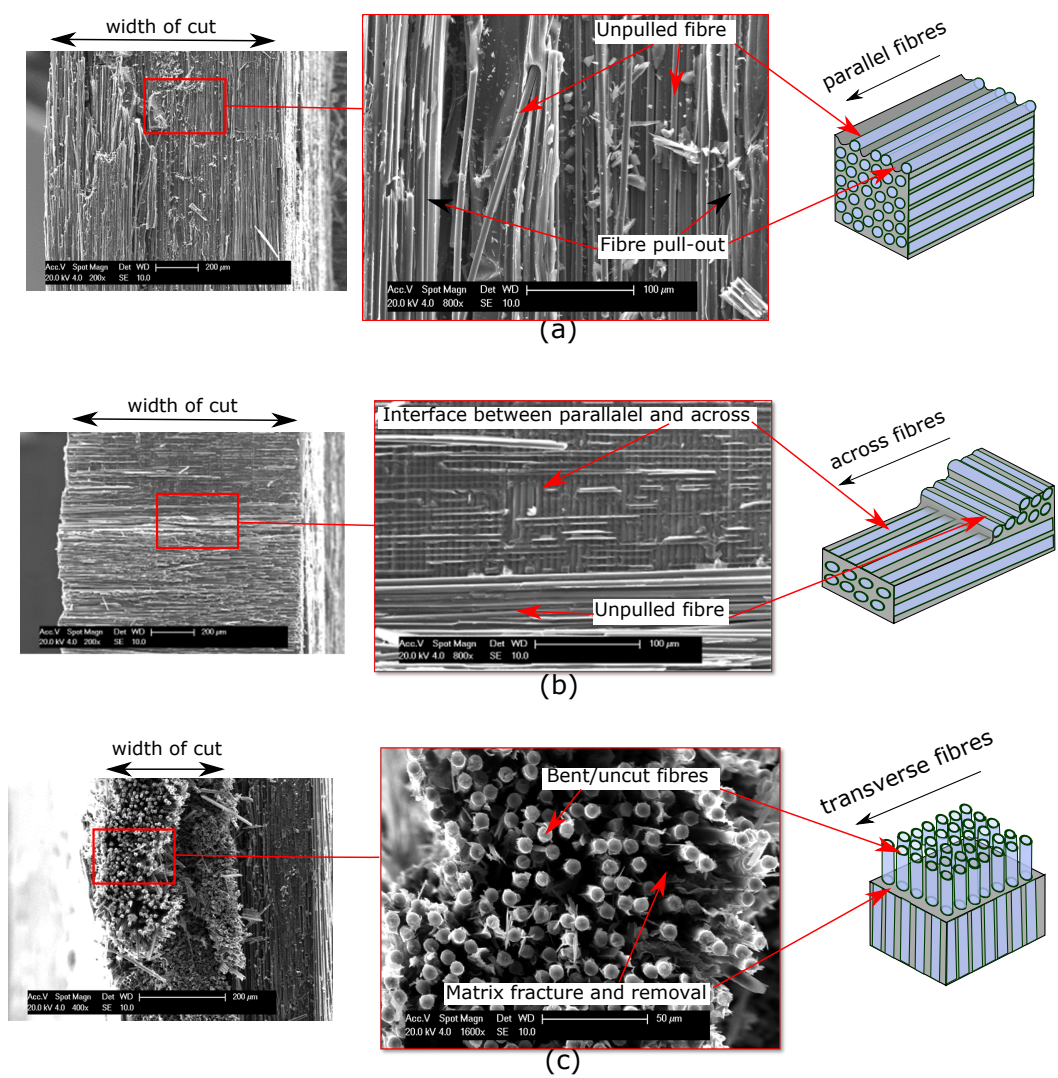

Figure 19: SEM analysis of the machined surface for brittle cutting in (a) longitudinal fibres (b) across fibres and (c) transverse fibres 


\subsection{Energy release rate in semi-ductile cutting}

The energy release rate in shear mode can be calculated using Eq24. As explained in the cutting modes section, in longitudinal fibres the ultimate shear strength $\left(\tau_{U S S}^{c o m p}\right)$ is higher than in across and transverse fibres $\left(\tau_{U S S}^{\text {mon }}\right)$ due to the inelastic behaviour. For longitudinal fibres an Ultimate Shear Stress of $\approx 45 \mathrm{MPa}$ has been found in the literature for a Carbon-Carbon [25]. On the other hand, a shear strength of a monolithic graphite $(\approx 16$ $\mathrm{MPa}$ ) has been used for across and transverse fibres [31]. Any effective analytical expression has not been found in the literature to describe the shear angle in cutting different fibres orientations. For this reason the energy release rate for shear cutting has been evaluated for the whole range of possible and common shear angles $\left(10^{\circ}<\phi<50^{\circ}\right)$.

From the results plotted in Fig 20, it is observed that the energy release rate for longitudinal and across fibres (green and blue respectively) have a similar magnitude: $G_{c, l o n g}=457 \pm 109 \mathrm{~N} / \mathrm{m}$ and $G_{c, \text { across }}=558 \pm 39$ $\mathrm{N} / \mathrm{m}$. On the other hand, while cutting transverse fibres, since the cutting path needs to break the fibres, the energy release rate needed is greater $\left(G_{c, \text { transv }}=1161 \pm 78 \mathrm{~N} / \mathrm{m}\right)$ and it is not any more the interlaminar but the translaminar fracture toughness. It is then affirmed that the equation Eq24 gives coherent results and it is applicable for cutting orthotropic materials during shear cutting.

\subsection{Comparison between the energy release rate in brittle and semi-ductile regimes}

A clear difference between the energy release rate for the fracture and shear cutting modes has been found. In the case of brittle cutting an approximated 10 times lower $\mathrm{G}$ is needed for the crack to propagate through the material. Therefore we can postulate that the Carbon/Carbon changes its fracture properties depending on the cutting behaviour. Similar obser- 


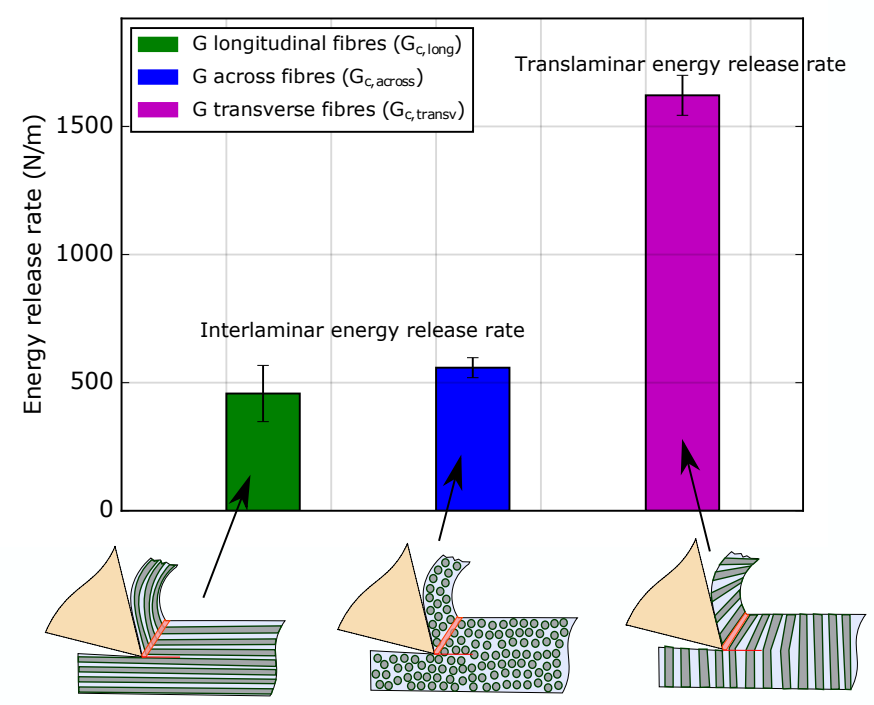

Figure 20: Average results for the energy release rate in shear cutting for the three cutting orientations

vations have been found in other materials, where the fracture toughness decreases when the material behaves more brittle due to a reduction of the testing temperature [32].

\section{Conclusion}

Ceramic Matrix Composites start to be a material choice for manufacturing components for several high values industries (i.e. aerospace and automotive) and therefore, an understanding of the mechanism by which they are machined is a key factor. The aim of the paper is to put the basis of the understanding on how the shear and fracture cutting mechanisms appear in orthotropic brittle materials such as the CMCs. The main points treated to achieve this goal are:

- An extensive experimental work in Carbon/Carbon has been performed including the three main fibre orientation that define the orthotropy of these materials: longitudinal, across and transverse. Unique cutting modes have been found for the three scenarios that 
have been theoretically explained based on the linear/bilinear properties of the CMCs in shearing conditions. Apart from a force sensor, a high imaging system and a vibration sensor have been used to understand the shear and fracture mechanism. The most relevant data acquired from these sensors has been used to explain the different cutting behaviours proving a brittle to semi-ductile transition suffered by CMCs.

- A novel analytical model for the brittle/fracture cutting has been developed specifically for each of the three cutting orientations. The analytical expression allows to calculate the energy release rate and has been validated based on the rising $\mathrm{R}$-curve that these composite materials posses in a brittle fracture domain. This agreement between the theoretical and experimental results confirm that the mechanism has been accurately modelled understanding the cutting mechanics for each of the three orientations.

- An analytical model for the shear cutting mode has been detailed with the aim of calculating the energy release rate in a semi-ductile mode. Positive results have been obtained for the different methods distinguishing between interlaminar fracture toughness (happening in longitudinal and across fibres) and translaminar fracture toughness (appearing in transverse fibres).

- A novel explanation on the variation of the fracture toughness between cutting methods has been found in CMCs. As defined for other fracture tests, the material can suffer from a ductile-to-brittle transition that can highly affect the fracture properties such as the energy release rate. This certitude might definitely need to be considered in future cutting models where the material suffer different cutting behaviours. 


\section{Acknowledgement}

The authors gratefully acknowledge Rolls Royce Plc for the funding support received during the work. A great thanks goes to Dr. Paul ButlerSmith and Mr. Zhirong Liao from University of Nottingham for their support in this work.

\section{References}

[1] R. Teti. Machining of Composite Materials. CIRP Annals - Manufacturing Technology, 51(2):611-634, 2002.

[2] Autar K. Kaw. Mechanics of composite materials. Taylor \& Francis, 2006.

[3] H. Hocheng. Machining technology for composite materials principles and practice. Woodhead Pub, 2012.

[4] Patrick Spriet. CMC Applications to Gas Turbines. In Ceramic Matrix Composites, chapter 21, pages 591-608. John Wiley \& Sons, Inc., Hoboken, NJ, USA, oct 2014.

[5] Walter Krenkel and Jacques Georges Thébault. Ceramic Matrix Composites for Friction Applications. In Ceramic Matrix Composites, chapter 23, pages 647-671. John Wiley \& Sons, Inc., Hoboken, NJ, USA, oct 2014 .

[6] Cédric Sauder. Ceramic Matrix Composites: Nuclear Applications. In Ceramic Matrix Composites, chapter 22, pages 609-646. John Wiley \& Sons, Inc., Hoboken, NJ, USA, oct 2014.

[7] Bernhard Heidenreich. C/SiC and $\mathrm{C} / \mathrm{C}-\mathrm{SiC}$ Composites. In Ceramic Matrix Composites, chapter 6, pages 147-216. John Wiley \& Sons, Inc., Hoboken, NJ, USA, oct 2014.

[8] Tony Atkins. Chapter 3 Simple Orthogonal Cutting of Floppy, Brittle and Ductile Materials. In The Science and Engineering of Cutting, chapter 3, pages 35-74. 2009.

[9] H Y Puw and H Hocheng. Chip formation model of cutting fiberreinforced plastics perpendicular to fiber axis. Transactions of ASME, 120(March 1996):192-196, 1998. 
[10] A. Sahraie Jahromi and B. Bahr. An analytical method for predicting cutting forces in orthogonal machining of unidirectional composites. Composites Science and Technology, 70(16):2290-2297, 2010.

[11] N. Bhatnagar, N. Ramakrishnan, N.K. Naik, and R. Komanduri. On the machining of fiber reinforced plastic (FRP) composite laminates. International Journal of Machine Tools and Manufacture, 35(5):701$716,1995$.

[12] X.M. Wang and L.C. Zhang. An experimental investigation into the orthogonal cutting of unidirectional fibre reinforced plastics. International Journal of Machine Tools and Manufacture, 43(10):1015-1022, 2003.

[13] S. Zenia, L. Ben Ayed, M. Nouari, and A. Delamézière. Numerical prediction of the chip formation process and induced damage during the machining of carbon/epoxy composites. International Journal of Mechanical Sciences, 90:89-101, 2015.

[14] R.E. Devor J.Samuel A.K. Srivastava K. Calzada, S.G. Kapoor. Modeling and interpretation of fiber orientation-based failure mechanisms in machining of carbon fiber-reinforced polymer composites. Journal of Manufacturing Processes, 14(2):141-149, 2012.

[15] G. Venu Gopala Rao, P. Mahajan, and N. Bhatnagar. Micromechanical modeling of machining of FRP composites Cutting force analysis. Composites Science and Technology, 67(3-4):579-593, 2007.

[16] J.G. Williams, Y. Patel, and B.R.K. Blackman. A fracture mechanics analysis of cutting and machining. Engineering Fracture Mechanics, $77(2): 293-308,2010$.

[17] Y. Patel, B. R K Blackman, and J. G. Williams. Determining fracture toughness from cutting tests on polymers. Engineering Fracture Mechanics, 76(18):2711-2730, 2009.

[18] Bing Wang, Zhanqiang Liu, and Qibiao Yang. Investigations of yield stress, fracture toughness, and energy distribution in high speed orthogonal cutting. International Journal of Machine Tools and Manufacture, 73:1-8, 2013.

[19] Z. Liao and D.A. Axinte. On chip formation mechanism in orthogonal cutting of bone. International Journal of Machine Tools 85 Manufacture, 102:41-55, 2016. 
[20] B. Cotterell, K. Hbaieb, J. G. Williams, H. Hadavinia, and V. Tropsa. The root rotation in double cantilever beam and peel tests. Mechanics of Materials, 38:571-584, 2006.

[21] T. G. Bifano, T. a. Dow, and R. O. Scattergood. Ductile-Regime Grinding: A New Technology for Machining Brittle Materials. Journal of Engineering for Industry, 113(2):184, 1991.

[22] S. Goel. The current understanding on the diamond machining of silicon carbide. Journal of Physics D: Applied Physics, 47(24):243001, 2014 .

[23] D. A. Axinte, S. Abdul Shukor, and A. T. Bozdana. An analysis of the functional capability of an in-house developed miniature 4-axis machine tool. International Journal of Machine Tools and Manufacture, 50(2):191-203, 2010.

[24] S. Baste. Inelastic behaviour of ceramic-matrix composites. Composites Science and Technology, 61(15):2285-2297, 2001.

[25] A. G. Evans and F. W. Zok. The physics and mechanics of fibrereinforced brittle matrix composites. Journal of Materials Science, 29(15):3857-3896, 1994.

[26] M.D. Thouless, A.G. Evans, M.F. Ashby, and J.W. Hutchinson. The edge cracking and spalling of brittle plates. Acta Metallurgica, 35(6):1333-1341, jun 1987.

[27] T. L. Anderson. Fracture Mechanics Fundamentals and Applications, Third Edition. CRC Press, 2005.

[28] S. Drapier J.M. Bergheau O. Klinkova, J. Rech. Characterization of friction properties at the workmaterial/cutting tool interface during the machining of randomly structured carbon fibers reinforced polymer with carbide tools under dry conditions. Tribology International, 44(12):2050-2058, 2011.

[29] M.Tanaka S. Ochiai N. Iwashita M. Hojo, T. Yamao and Y. Sawada. Effect of Interface Control on Mode I Interlaminar Fracture Toughness of Woven C/C Composite Laminates. JSME International Journal Series A, 44(4):573-581, 2001.

[30] M. Tanaka S. Ochiai M. Hojo, T. Yamao, N. Iwashita, and Y.Sawada. Effects of Interface Control and Heat-Treatment Temperature on Interlaminar Shear Strength and Mode II Interlaminar Fracture Toughness of Woven C/C. Material Science Research International, 7:34-40, 2001. 
[31] F. L. Neto L. G. B. Manhani, L. C. Pardini. Assessement of tensile strength of graphites by the Iosipescu coupon test. Materials Research, 10(3):233-239, 2007.

[32] Y. J. Chao, J. D. Ward, and R. G. Sands. Charpy impact energy, fracture toughness and ductile-brittle transition temperature of dualphase 590 Steel. Materials and Design, 28(2):551-557, 2007. 